\title{
A new device for endoscopic submucosal dissection of a submucosal gastrointestinal stromal tumor
}

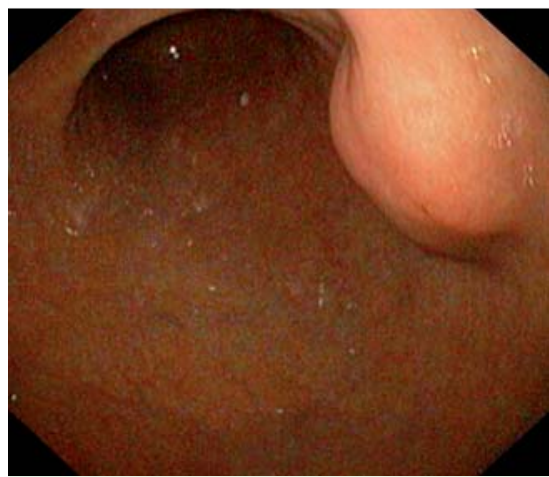

Fig. 1 Endoscopic appearance of the submucosal gastrointestinal stromal tumor at the posterior wall of the proximal part of the gastric antrum.
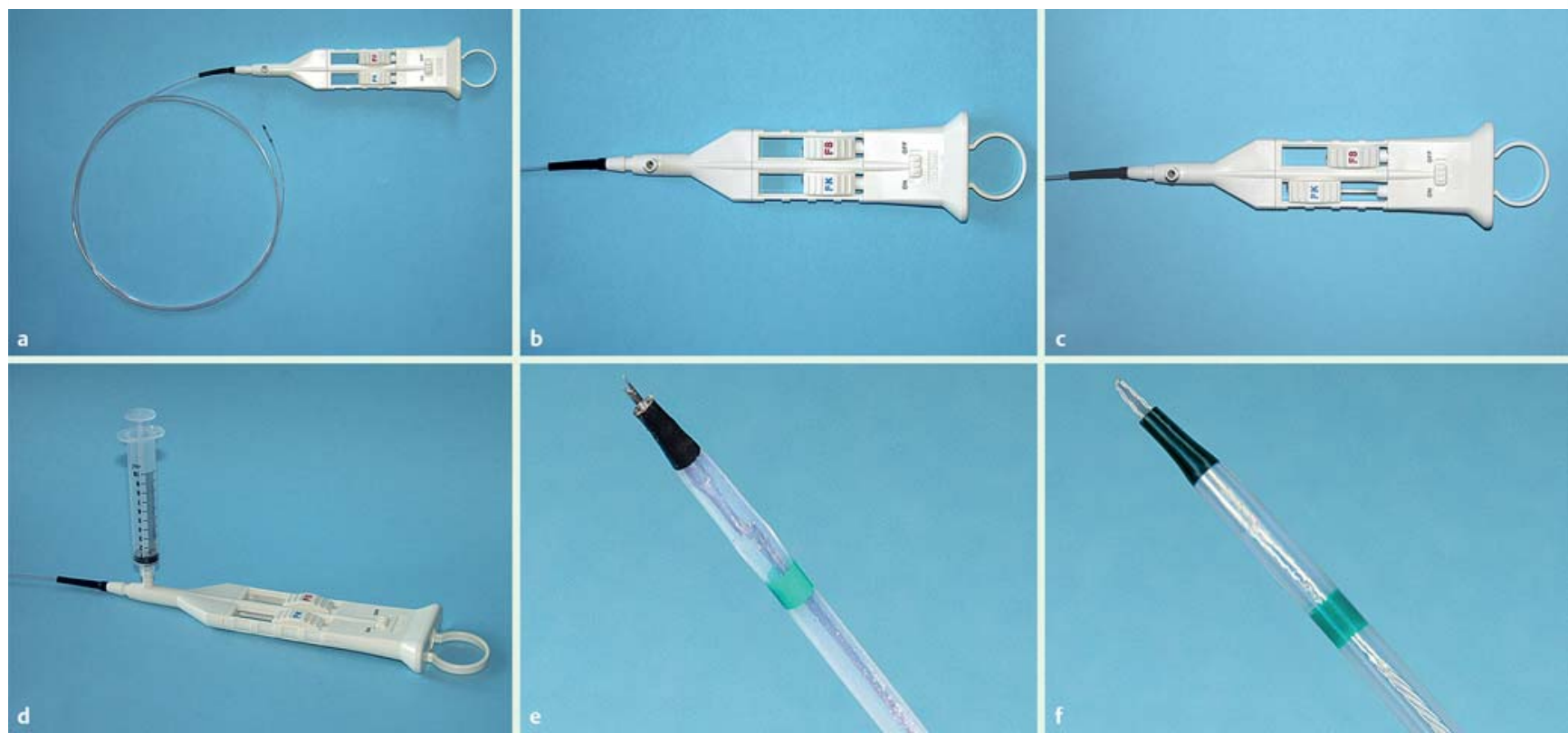

Fig. 3 a The Endo-FS/FK device. $\mathbf{b}$ Handle of the device with different sliders to control both parts (FK tip and FS tip) of the device. $\mathbf{c}$ Slider of the handle in the position in which the forklike needle (FK tip) is moved out. $\mathbf{d}$ The syringe for injecting and rinsing connected to the handle. $\mathbf{e}$ The forklike injection needle (FK tip). $\mathbf{f}$ The braided snare tip (FS tip) of the dissection device.

Surgical resection is the treatment of the choice for gastrointestinal stromal tumors (GIST). These neoplasms usually arise from the muscularis propria. Endoscopic submucosal dissection (ESD) is a novel technique to resect epithelial as well as submucosal gastrointestinal neoplasia and represents a less invasive alternative to surgery [1-3]. Recently, many technical developments and accessories have been presented to facilitate the ESD procedure [3-5]. The following case report presents the successful ESD of a submucosal gastric GIST using a new combined instrument, the Endo-FS/FK dissection device (KACHU Technology, Seoul, Korea), which integrates an injection needle and a flex knife into a single device.

A submucosal tumor, $15-20 \mathrm{~mm}$ in size, was incidentally found in the stomach of a 72-year-old man. The lesion was located at the posterior wall in the proximal part of the gastric antrum ( $\bullet$ Fig. 1). Endoscopic ultrasound revealed a $15 \mathrm{~mm}$ homogeneous tumor, presumably of a benign or premalignant nature (lipoma, leiomyoma, or GIST) ( $\bullet$ Fig. 2). As the patient refused surgery, ESD was carried out using the new combination dissection device, the Endo-FS/FK ( $\bullet$ Fig. 3; $\bullet$ Video 1 ). The whole procedure (marking, injection, dissection) was carried out using only this instrument. After marking with the flexible snare tip, a high-volume submucosal injection was given, using the integrated injection needle of the Endo-FS/FK device. 

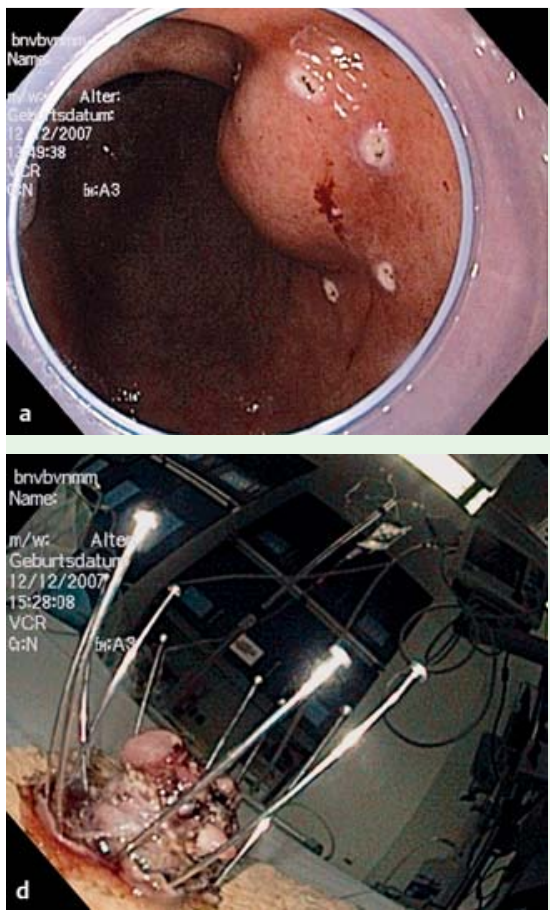

A dilute epinephrine solution with indigo carmine dye ( $1 \mathrm{mg}$ epinephrine and $1 \mathrm{~mL}$ $0.8 \%$ indigo carmine in $250 \mathrm{~mL} 0.9 \%$ saline solution) was used to broaden the submucosal layer. A circumferential incision was made with the flexible snare tip of the Endo-FS/FK device. Subsequently, the dissection with the flexible snare tip was interrupted by injections of the dilute epinephrine and indigo carmine solution, again using the integrated injection needle. Thus, time-consuming changing of accessories was avoided and the whole tumor was dissected with the flexible snare tip of the Endo-FS/FK device. Finally, hemostasis of oozing bleeding was achieved with a Coagrasper device (Olympus Endo-

\section{Video 1}

Demonstration of the endoscopic submucosal dissection procedure using the Endo-FS/FK device. In conclusion, ESD should be considered as a therapeutic alternative not only in early gastric cancer but also in selected cases with submucosal tumors. The new combined instruments, such as the Endo-FS/FK device, are facilitating the resection procedure.
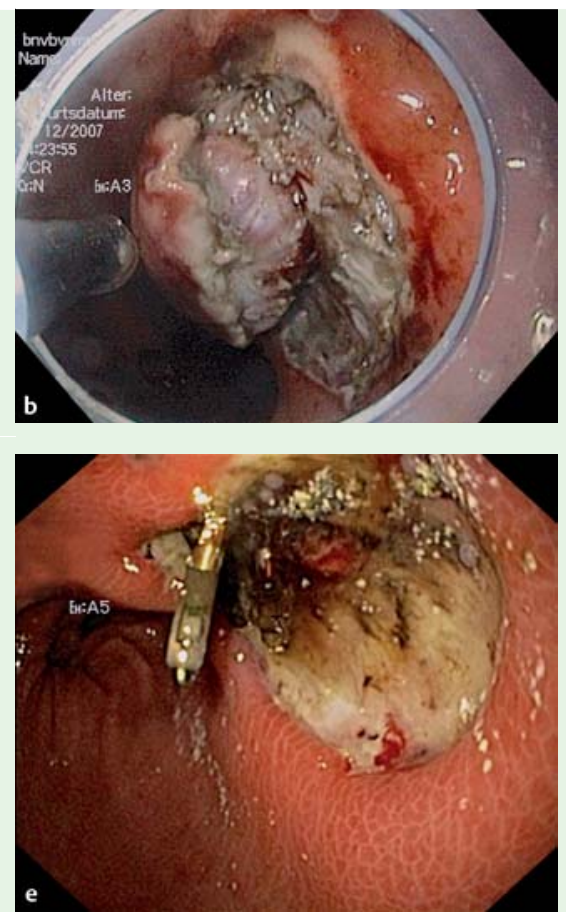

therapy, Hamburg, Germany). Histological examination of the resection specimens revealed a $15 \mathrm{~mm}$ GIST with a proliferation rate of $2-3 \%$ (MIB1). In addition, the tumor expressed CD117 and CD34 markers, and so the patient's situation was determined to be low risk. A control gastroscopy 1 day later revealed an arterial stump in the center of the resection ulcer. Three endoclips (HX-610-090, Olympus Endotherapy, Hamburg, Germany) were applied for hemostasis ( $\bullet$ Fig. 4). The patient recovered rapidly and was discharged 48 hours after resection. Followup 1 and 3 months after resection showed regular healing without any signs of recurrence.

\section{Endoscopy_UCTN_Code_TTT_1AO_2AG}

\section{E. Busch ${ }^{1}$, B. Mueller ${ }^{1}$, E. G. Hahn ${ }^{1}$, M. Raithel ${ }^{1}$, J. Maiss ${ }^{1,2}$}

1 Department of Medicine I, University of Erlangen-Nuremberg, Erlangen, Germany

2 Gastroenterology Clinic, Forchheim, Germany

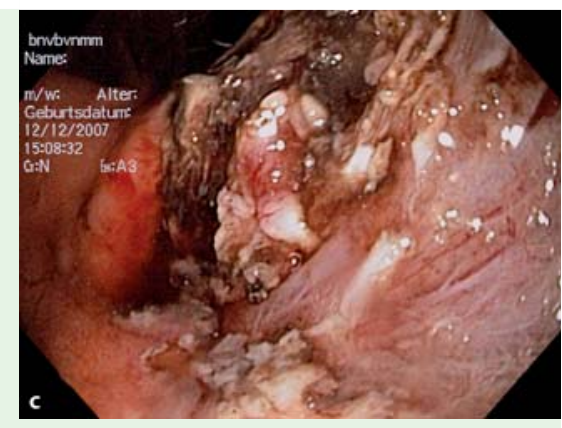

Fig. 4 a The resection margin was marked by creating small coagulation dots with the snare tip. b Lesion after complete incision with the snare tip. c Resection area after complete removal of the tumor. $\mathbf{d}$ The GIST specimen pinned on a cork plate for pathological workup. e One day after the resection: an ulcer is seen with a clip applied on a central vessel.

\section{References}

1 Kakushima N, Fujishiro M, Kodashima S et al. A learning curve for endoscopic submucosal dissection of gastric epithelial neoplasms. Endoscopy 2006; 38: $991-995$

2 Lee IL, Lin PY, Tung SY et al. Endoscopic submucosal dissection for the treatment of intraluminal gastric subepithelial tumors originating from the muscularis propria layer. Endoscopy 2006; 38: 1024-1028

3 Rosch T. Endoscopic submucosal dissection (ESD): an overview of articles in this issue. Endoscopy 2006; 38: 978-979

4 Kume K, Yamasaki M, Kanda $K$ et al. Endoscopic submucosal dissection using a novel irrigation wiper-knife. Endoscopy 2007; 39 Suppl 1: E144

5 Neuhaus H, Costamagna G, Deviere J et al. Endoscopic submucosal dissection (ESD) of early neoplastic gastric lesions using a new double-channel endoscope (the "R-scope"). Endoscopy 2006; 38: 1016-1023

Bibliography

DOI $10.1055 / \mathrm{s}-0029-1214929$

Endoscopy 2009; 41: E238 -E239

(c) Georg Thieme Verlag KG Stuttgart · New York . ISSN 0013-726X

\section{Corresponding author}

PD Dr. J. Maiss, MD

Gastroenterology Clinic Dr. Kerzel/PD Dr. Maiss Mozartstr. 1

D-91301 Forchheim

Germany

Fax: +49-9133-602618

juergen.maiss@uk-erlangen.de;

j.maiss@t-online.de 